\title{
The EB-DNA Liquid Crystalline Complex with High Concentration of $\mathbf{M g}^{2+}$
}

\author{
Bo Liao, ${ }^{1,2}$ Benqiao He, ${ }^{1,2}$ Shouxi Chen, ${ }^{1}$ and Yong HuAng ${ }^{1,3, \dagger}$ \\ ${ }^{1}$ State Key Laboratory of Polymer Physics and Chemistry, Joint Laboratory Polymer Science and Material, \\ Institute of Chemistry, Chinese Academy of Science, Beijing 100080 China \\ ${ }^{2}$ Graduate School, Chinese Academy of Sciences, Beijing 100039, China \\ ${ }^{3}$ Laboratory of Cellulose and Lignocellulosics Chemistry, Guangzhou Institute of Chemistry, \\ Chinese Academy of Sciences, Guangzhou 510650, China
}

(Received January 13, 2006; Accepted February 17, 2006; Published May 25, 2006)

\begin{abstract}
The effects of ethidium bromide (EB) on the DNA cholesteric phase in the high ionic strength of $\mathrm{Mg}^{2+}$ were investigated by polarized optical microscopy (POM), ${ }^{31} \mathrm{P}$ and ${ }^{23} \mathrm{Na}$ nuclear magnetic resonance (NMR). It was found that the cholesteric pitch in the EB-DNA cholesteric phase is obviously smaller than that in the EB-free DNA cholesteric solutions with the same ionic strength of $\mathrm{Mg}^{2+}$ at room temperature. The fraction of liquid crystal phase in both the EB-free and the EB-DNA solutions is decreased with increasing the $\mathrm{Mg}^{2+}$ concentration. But the fraction of liquid crystal phase in the EB-DNA solutions is higher than that in the EB-free DNA solutions at the same $\mathrm{Mg}^{2+}$ concentration, which is attributed to the change of the surface charge distribution on the DNA chains and the stiffness of DNA due to intercalation of EB. The results of the ${ }^{23} \mathrm{Na}$ NMR experiments suggested that the intercalation of EB results in the changes of the ionic environment close to the DNA chains, by which the liquid crystal behavior of DNA is affected. [doi:10.1295/polymj.PJ2005210]

KEY WORDS DNA / Cholesteric Phase / Liquid Crystal /
\end{abstract}

DNA is a right-handed double helix rod macromolecule, which is widely studied from theory ${ }^{1-3}$ to application..$^{4-7}$ It can spontaneously undergo a transition from the isotropic phase to the liquid crystal state above the critical concentration. ${ }^{8-11}$ Although the critical concentration is high, the local concentration of the DNA in vivo can be quite large and the liquid crystal phase of the DNA is formed locally. The formation of the liquid crystalline phase may play some role in the packing of DNA chains in some biological system. Many studies on DNA liquid crystals have got an insight into the main features of the organization of the DNA in vivo and shed light on its biological role. ${ }^{12-14}$ In the DNA cholesteric phase, the local orientation direction of the DNA chains is perpendicular to the cholesteric axis, which regularly rotates with a constant twist. This molecular arrangement of the DNA chains is influenced by many factors, such as ionic strength, temperature, the length of DNA chains and small molecule binding with the DNA chains,,${ }^{15-17}$ etc.

Ethidium bromide (EB) is a kind of fluorescence dye molecule, which is a carcinogen, and its molecular structure is shown in Figure 1. It can intercalate between DNA successive base pairs and induce to mistake when DNA is copied by itself. In vivo, the packing of the DNA chains is very similar to the DNA cholesteric phase. The investigation of the EB influence on the liquid crystalline behavior of DNA may

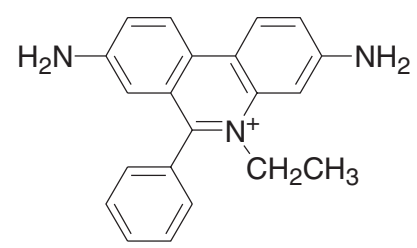

Figure 1. The molecular structure of EB.

help us to understand the carcinogenic origin in the liquid crystalline viewpoint, and to understand the origin of cholesteric phase of DNA in molecular viewpoint. Many investigations of the effects of the EB on the DNA liquid crystalline behavior have been reported. ${ }^{18-20}$ There is high concentration of $\mathrm{Mg}^{2+}$ in the cell nucleus and it is very factual to investigate the influence of EB on the liquid crystal behavior of DNA when there exits $\mathrm{Mg}^{2+}$. But the effects of the coexistence of both $\mathrm{Mg}^{2+}$ and EB on the DNA liquid crystalline properties are not well studied. In this paper, the influence of EB on the liquid crystal behavior of the DNA solutions with the existence of $\mathrm{Mg}^{2+}$ was discussed.

\section{EXPERIMENTAL}

Salmon sperm NaDNA ( $6.25 \%$ of Na) was purchased from Sigma and used as received, $M_{\mathrm{n}}<10^{6}$ $(<2000 \mathrm{bp})$. EB was purchased from Sigma. EB-

${ }^{\dagger}$ To whom correspondence should be addressed (Tel: +86-10-68597350, Fax: +86-10-68597356, E-mail: yhuang@ cashq.ac.cn). 

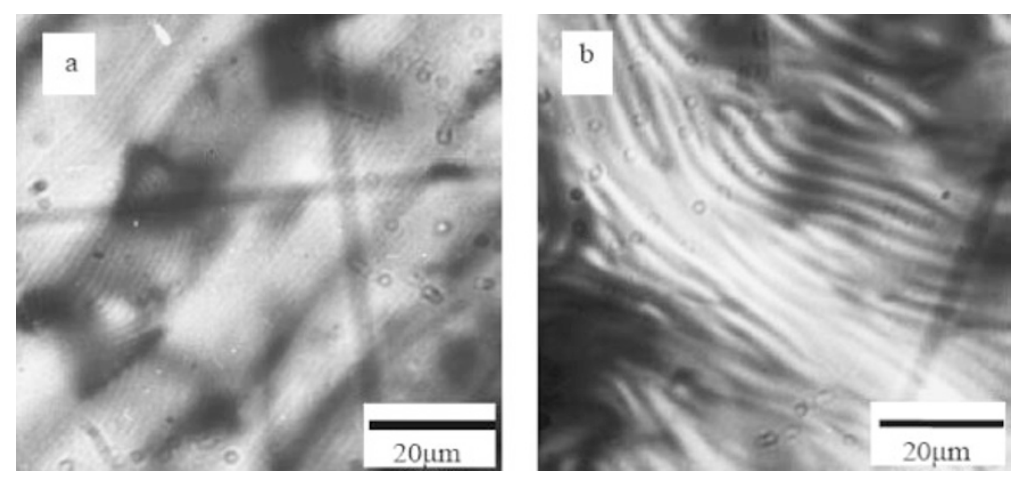

Figure 2. Micrographs of DNA solutions, $\mathrm{C}_{\mathrm{DNA}}=220 \mathrm{mg} / \mathrm{mL}, \mathrm{C}_{\mathrm{Mg}^{2+}}=0.25 \mathrm{M}, \mathrm{a}: \mathrm{C}_{\mathrm{EB}} / \mathrm{C}_{\mathrm{bpDNA}}=1 / 11 ; \mathrm{b}: \mathrm{C}_{\mathrm{EB}}=0$.

DNA solutions were prepared according to the following procedure: (a) Amount of EB was added from an aqueous stock solution to amount of NaDNA solution and placed for adequate time in order to obtain homogenous samples. (b) The EB-DNA solution was lyophilized. (c) The dried complex was dissolved in a 5-mm NMR tube with $500 \mu$ Tris-EDTA buffer containing the amount of $\mathrm{MgCl}_{2}$. (d) The final solutions were mixed by repeated heating and centrifugation. All DNA solutions were allowed to equilibrate for at least 30 days before NMR experiments. The DNA solutions were sandwiched between two slides and sealed with wax. All of the samples were equilibrated for at least 15 days and observed under POM (Olympus $\mathrm{BH}-2$ ) at room temperature.

${ }^{31} \mathrm{P}$ and ${ }^{23} \mathrm{Na}$ spectra were recorded on Bruker AV400 and DMX-300 NMR spectrometer, respectively. ${ }^{31} \mathrm{P}$ NMR spectra were acquired with gated proton decoupling, the $90^{\circ}$ pulse of $6.3 \mu \mathrm{s}, 400 \mathrm{ppm}$ of spectra width and 6400 transients. ${ }^{23} \mathrm{Na}$ spectra were recorded using a simple pulse sequence of the $90^{\circ}$ pulse of $6.5 \mu \mathrm{s}$, a spectra width of $200 \mathrm{ppm}$ and 64 transients. All spectra were taken on nonspinning sample. $\mathrm{T}_{1}$ relaxation times of ${ }^{23} \mathrm{Na}$ were measured by the standard inversion recovery pulse sequence.

\section{RESULTS AND DISCUSSION}

Figure 2 is the POM micrographs of the EB-DNA and EB-free DNA solutions at the concentration of $220 \mathrm{mg} / \mathrm{mL}$ with $0.25 \mathrm{~mol} / \mathrm{L}$ of $\mathrm{Mg}^{2+}$. It can be seen that the pitch of the cholesteric phase is about $2.5 \mu \mathrm{m}$ in the EB-DNA solution (Figure 2a), while the pitch is $7 \mu \mathrm{m}$ in the EB-free DNA solution (Figure 2b). The results indicate that the pitch of the cholesteric phase of the DNA solution becomes smaller when the EB molecules intercalate to DNA chains. It is believed that the smaller pitch in the EB-DNA cholesteric solution is due to the stereo chemical effect of the intercalation of EB. ${ }^{18}$ DNA is a polyelectrolyte with negative charges and the variation of the pitch should be related to the electrostatic twisted force besides the stereo chemical effect of the intercalation of the EB molecules, because the twisted force in the DNA cholesteric phase originates partly from electrostatic twisted force between DNA chains. ${ }^{21-23}$ The primary targets of magnesium ions on the DNA binding sites are the phosphate groups on DNA chains. ${ }^{24-26}$ Negative charges of DNA chains are partly neutralized by $\mathrm{Mg}^{2+}$ and thus the linear charge density of the DNA chain is decreased when $\mathrm{Mg}^{2+}$ exists in the system, which results in the decrease of the electrostatic twisted force. While, the binding of $\mathrm{Mg}^{2+}$ to the DNA chains may be partly blocked in the EB-DNA systems due to the intercalation of EB molecules into DNA chains, which results in the decrease of the binding chance of $\mathrm{Mg}^{2+}$ with DNA chains. The linear charge density of the DNA chain in the EB-DNA solution with $\mathrm{Mg}^{2+}$ is greater than that in the EB-free DNA solution with $\mathrm{Mg}^{2+}$, because the neutralization ability of the monovalent EB is weaker than $\mathrm{Mg}^{2+}$. Therefore, the electrostatic twisted force in the EB-DNA solution with $\mathrm{Mg}^{2+}$ is greater than that in the EB-free DNA solution with the same concentration of $\mathrm{Mg}^{2+}$, which results in the smaller pitch in the EB-DNA solution with $\mathrm{Mg}^{2+}$ compared with the EB-free DNA solution with $\mathrm{Mg}^{2+}$.

${ }^{31} \mathrm{P}$ NMR spectra of EB-free DNA liquid crystal solutions with the concentration of $\mathrm{Mg}^{2+}$ of $0,0.125$, $0.25 \mathrm{~mol} / \mathrm{L}$ are shown in Figure $3 \mathrm{a}, 3 \mathrm{~b}$ and $3 \mathrm{c}$, respectively. In Figure $3 \mathrm{a}$, the spectrum has a broad peak with a needle-like peak (denoted as 1) at the downfield, and it is believed that the needle-like peak 1 is attributed to the resonance of free phosphate group originated from the fission of DNA in our experiments. While in Figure $3 b$ and $3 c$, the spectrum is consisted of a main broad resonance and a sharp downfield signal besides the small peak 1 . With increasing the $\mathrm{Mg}^{2+}$ concentration, the narrower downfield signal became broader, while the main broad peak becomes narrow. The ${ }^{31} \mathrm{P}$ NMR spectra of the EB-DNA liquid crystal solutions with the concentration of $\mathrm{Mg}^{2+}$ of 0 , $0.125,0.25 \mathrm{~mol} / \mathrm{L}$ are shown in Figure $3 \mathrm{~d}, 3 \mathrm{e}$ and $3 \mathrm{f}$, respectively. The intensity of needle-like peak 1 in the 


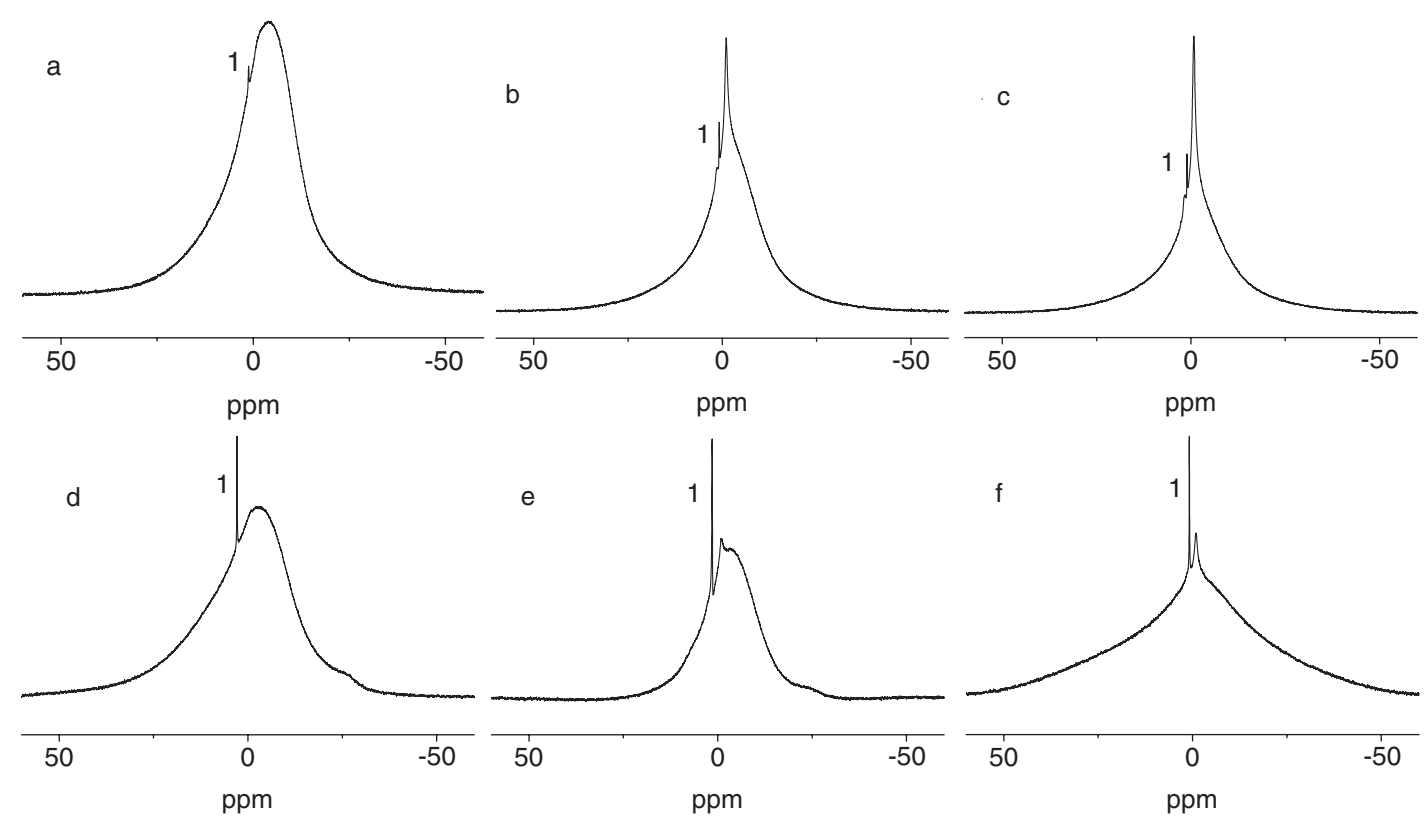

Figure 3. ${ }^{31} \mathrm{P}$ NMR spectra of DNA. $\mathrm{C}_{\mathrm{DNA}}=250 \mathrm{mg} / \mathrm{mL}, \mathrm{a}: \mathrm{C}_{\mathrm{Mg}}{ }^{2+}=\mathrm{C}_{\mathrm{EB}}=0 ; \mathrm{b}: \mathrm{C}_{\mathrm{EB}}=0, \mathrm{C}_{\mathrm{Mg}}{ }^{2+}=0.125 \mathrm{M} ; \mathrm{c}: \mathrm{C}_{\mathrm{EB}}=0$, $\mathrm{C}_{\mathrm{Mg}}{ }^{2+}=0.25 \mathrm{M} ; \mathrm{C}_{\mathrm{EB}} / \mathrm{C}_{\mathrm{bpDNA}}=1 / 11, \mathrm{C}_{\mathrm{Mg}}{ }^{2+}$ are $0,0.125 \mathrm{M}, 0.25 \mathrm{M}$ in d, e, f respectively.

EB-DNA solution becomes stronger than that of EBfree DNA solution, which shows the increase of the amount of free phosphate groups because EB may promote the fission of DNA chains. The broad peak of the EB-DNA solutions without $\mathrm{Mg}^{2+}$ (Figure 3d) is the same as that in the EB-free DNA solution without $\mathrm{Mg}^{2+}$ (Figure 3a). At the same concentration of $\mathrm{Mg}^{2+}$, the narrow downfield resonance of the EBDNA solutions (Figures $3 e$ and $3 f$ ) is narrower than that of EB-free DNA solutions (Figures $3 b$ and $3 c$ ), and the broad resonance in Figures $3 \mathrm{e}$ and $3 \mathrm{f}$ is broader than that in Figures $3 b$ and $3 c$. Moreover, a highfield shoulder appears in the EB-DNA solutions, similar to the report. ${ }^{20}$

When the liquid crystal phase and the isotropic phase co-exist in the DNA solution, the ${ }^{31} \mathrm{P}$ NMR spectrum of DNA solution should be a main broad peak superimposed on a narrower downfield peak. ${ }^{27,28}$ The narrow downfield peak results from the rapid tumbling motions of the DNA chains, which averages out the ${ }^{31} \mathrm{P}$ chemical shift anisotropy. And the broad peak, which is attributed to the distribution of resonances of the DNA chains in the anisotropic phase, originates from restricted molecular motions and only is partially averaged out. The fraction of the two phases in the solution is proportional to the integral area of the two peaks, respectively. The remarkable enhancement of the relative intensity of the downfield resonance with increasing $\mathrm{Mg}^{2+}$ concentration suggests the growth of the isotropic phase in the DNA solution. Therefore, the formation of the isotropic phase is promoted by $\mathrm{Mg}^{2+}$ and it shows again that the electrostatic interactions from $\mathrm{Mg}^{2+}-\mathrm{PO}^{4+}$ is very important to decrease the fraction of the liquid crystal phase in the system. In the EB-DNA solutions, the relative intensity of the downfield resonance is increased with increasing $\mathrm{Mg}^{2+}$ concentrations too (Figures 3d, 3e and 3f). However, the increment of the intensity of the downfield resonance in the EB-DNA solution is smaller than that in the EB-free DNA solution at the same $\mathrm{Mg}^{2+}$ concentration. It is revealed that the fraction of the anisotropic phase in the EB-DNA solution is higher than that in the EB-free DNA solution with the same $\mathrm{Mg}^{2+}$ concentration. It is believed that the effective diameter of the DNA chains in the EBDNA solution is bigger than that in the EB-free DNA solution, because there is a higher linear charge density on the DNA chains in the EB-DNA solution than that in the EB-free DNA solution. The bigger the effective diameter of DNA is, the lower the critical concentration of liquid crystal phase transition is. ${ }^{29,30}$ Thus, the fraction of liquid crystal phase in the EBDNA solution is higher than that in the EB-free DNA solution when the concentration is the same. Furthermore, the DNA chains are more rigidity ${ }^{31,32}$ in the EB-DNA solution than those in the EB-free DNA solution due to the intercalation of EB, which also results in the decrease of the critical concentration of DNA liquid crystalline phase formation or the increase of the fraction of the liquid crystalline phase in the solution at the same concentration. ${ }^{30,33}$

The effect of EB on the ionic environment around DNA chains can be confirmed by ${ }^{23} \mathrm{Na}$ NMR spectrum. Figure 4 shows the ${ }^{23} \mathrm{Na}$ NMR spectra of the EB-free DNA and the EB-DNA solutions. It can be seen from Figure $4 \mathrm{a}$ that the peak of the ${ }^{23} \mathrm{Na}$ NMR 

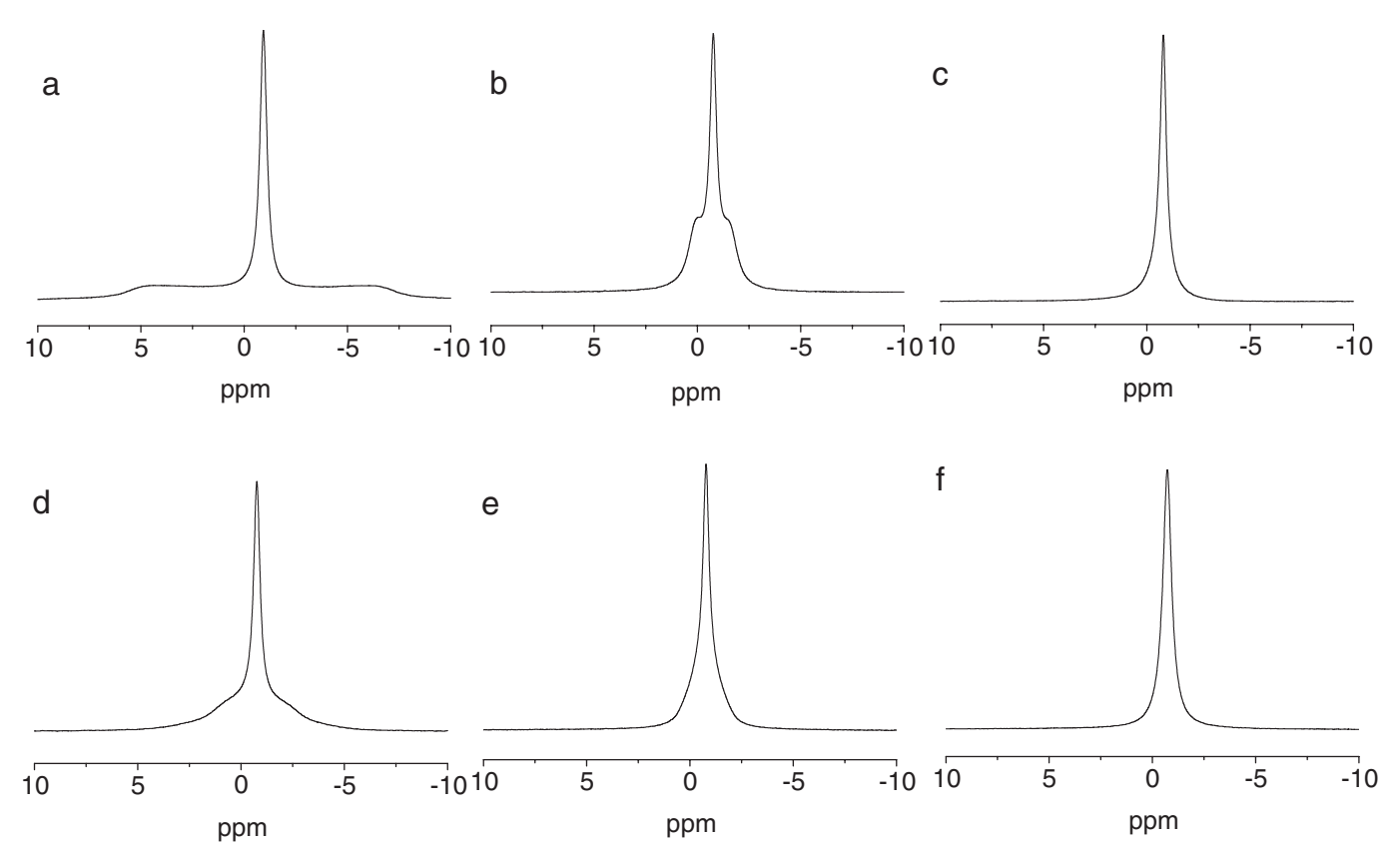

Figure 4. ${ }^{23} \mathrm{Na} N M R$ spectra of DNA solution $\mathrm{C}_{\mathrm{DNA}}=250 \mathrm{mg} / \mathrm{mL}, \mathrm{a}: \mathrm{C}_{\mathrm{Mg}}{ }^{2+}=\mathrm{C}_{\mathrm{EB}}=0$; b: $\mathrm{C}_{\mathrm{EB}}=0, \mathrm{C}_{\mathrm{Mg}}{ }^{2+}=0.125 \mathrm{M}$; $\mathrm{c}$ : $\mathrm{C}_{\mathrm{EB}}=0$, $\mathrm{C}_{\mathrm{Mg}}{ }^{2+}=0.25 \mathrm{M} ; \mathrm{C}_{\mathrm{EB}} / \mathrm{C}_{\mathrm{bpDNA}}=1 / 11, \mathrm{C}_{\mathrm{Mg}}{ }^{2+}$ are $0,0.125 \mathrm{M}, 0.25 \mathrm{M}$ in d, e, f respectively.

spectrum splits into three peaks symmetrically in the EB-free DNA solutions. But the splitting of ${ }^{23} \mathrm{Na}$ NMR spectrum decreases with increasing the $\mathrm{Mg}^{2+}$ concentration and there are no splitting peaks in the spectrum when $\mathrm{Mg}^{2+}$ concentration is 0.25 $\mathrm{mol} / \mathrm{L}$. In the EB-DNA solutions, the splitting of the peak can be observed (Figure 4d) but it is much smaller than that in the EB-free DNA solution when there is no $\mathrm{Mg}^{2+}$ in the system. When $\mathrm{Mg}^{2+}$ exists in the system, the splitting of the peak in the spectra almost disappears. It is suggested that the existence of both EB and $\mathrm{Mg}^{2+}$ confines the peak splitting in the ${ }^{23} \mathrm{Na}$ NMR spectra for DNA solutions. ${ }^{23} \mathrm{Na}$ is a quadrupolar nucleus $(I=3 / 2)$. In the DNA liquid crystalline phase, the anisotropy results in non-zero average of the electric field gradients around the nucleus, because of the static quadrupolar interaction between the nuclear moment and the electric gradient. The NMR spectrum of ${ }^{23} \mathrm{Na}$ nucleus exhibits a multiple of $2 \mathrm{I}=3$ equally spaced peaks. ${ }^{34}$ The separation between adjacent lines, the quadrupolar splitting $(\Delta v)$, depends on several factors, such as the quadrupolar interaction strength and the alignments of the DNA chains, etc. In the solutions, the splitting of ${ }^{23} \mathrm{Na}$ nucleus in different sites is different and the ${ }^{23} \mathrm{Na}$ nuclei are rapidly exchanged in different anisotropic magnetic environments. Accordingly, the observed splitting $\Delta v$ is the weighted average in each site. The analysis of the observed ${ }^{23} \mathrm{Na}$ NMR splitting is commonly done by means of a two-site model according to that the counter ions are exchanged between a "bound" state in the immediate vicinity of DNA chains and a "free" state where the electric field gradient at the sodium nucleus is essentially unaffected. ${ }^{34}$ In the "free" state, the splitting $\Delta v$ averages to zero due to the fast reorientation of molecules. When the exchange of the ${ }^{23} \mathrm{Na}$ nuclei is fast on the NMR time scale, the observed splitting $\Delta v$ is the number averages of the splitting in the two states, as is given ${ }^{20}$

$$
\Delta v=P_{\mathrm{B}} \Delta v_{\mathrm{B}}
$$

Where $P_{\mathrm{B}}$ is the fraction of the sodium and $\Delta v_{\mathrm{B}}$ is the averages quadrupolar splitting in the bound state. Accordingly, in the EB-free DNA solutions, with increasing the amount of $\mathrm{Mg}^{2+}$, the decrease of quadrupolar splitting can be mainly related to the decrease of the amount of $\mathrm{Na}^{+}$in the bound state due to competing of $\mathrm{Mg}^{2+}$. In the DNA solutions with EB, the quadrupolar splitting is not zero only when there is no $\mathrm{Mg}^{2+}$ in the system, but it is smaller than that in the EB-free systems. It is believed that the decrease of the quadrupolar splitting in the EB-DNA solutions mainly result from the decrease of the amount of $\mathrm{Na}^{+}$in bound state. When $\mathrm{Mg}^{2+}$ exists in the EBDNA systems, the amount of $\mathrm{Na}^{+}$in bound state is decreased markedly because the EB blocks the combination of the DNA chains with $\mathrm{Na}^{+}$. So the quadrupolar splitting is decreased to zero.

The ionic atmosphere variation around DNA chains, due to the EB binding to DNA chains is confirmed once again by the longitudinal relaxation rates $R_{1}$ of ${ }^{23} \mathrm{Na}$ NMR. Figure 5 shows that $R_{1}$ is linearly decreased with increasing the $\mathrm{Mg}^{2+}$ in both EBDNA and EB-free DNA solutions. But the value of $R_{1}$ in the EB-free systems is bigger than that in the EB-DNA systems at the same $\mathrm{Mg}^{2+}$ concentration. It 


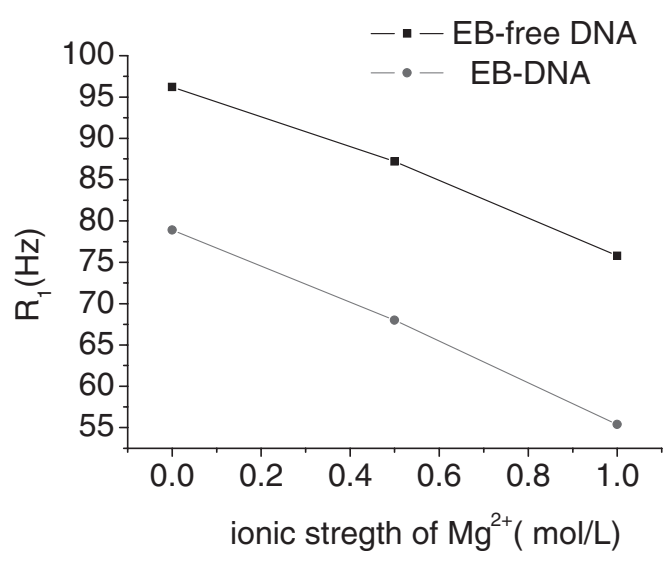

Figure 5. The ${ }^{23} \mathrm{Na}$ longitudinal relaxation rate $R_{1}$ in EB-free and EB-DNA samples.

has been known that the value of $R_{1}$ depends on the interaction between its nuclear electric quadrupolar moment and the fluctuating electric field gradient, originating from the nearby distribution of electrons and nuclei. Here, a single-exponential law to measure $R_{1}$ of ${ }^{23} \mathrm{Na}$ NMR and the two-site model are simply used according to the literatures. ${ }^{17,35}$

The $R_{1}$ is given: ${ }^{17}$

$$
R_{1}=R_{\mathrm{f}}+\left(R_{\mathrm{b}}-R_{\mathrm{f}}\right) r[(\mathrm{P}) /(\mathrm{Na})]
$$

where $R_{\mathrm{f}}, R_{\mathrm{b}}$ are the relaxation of ${ }^{23} \mathrm{Na}$ in free state and bound state, respectively; $r$ is the fraction of bound sodium ions per nucleotide phosphate, and (P) and $(\mathrm{Na})$ are the molar concentrations of DNA phosphate and total sodium ions, respectively. As defined by NMR criteria, bound ions are sufficiently near the DNA chains (about $4 \AA$ ) to have relaxation rates $R_{\mathrm{b}}$ which is much greater than $R_{\mathrm{f}}$. Therefore, if $(\mathrm{P}) /(\mathrm{Na})$ is constant and $R_{\mathrm{f}}$ and $R_{\mathrm{b}}$ are unchanged, the $R_{1}$ is linearly increased with increasing the fraction of the bound sodium ions $r$. In our experiments, $(\mathrm{P}) /(\mathrm{Na})$ is identical in all samples. Accordingly, in all kinds of EB-free DNA and EB-DNA systems, the decrease of the $R_{1}$ mainly results from the decrease of the fraction of bound sodium ions $r$ with increasing the amount of $\mathrm{Mg}^{2+}$. In comparing $R_{1}$ of EB-free DNA systems with that of EB-DNA systems at the same concentration of $\mathrm{Mg}^{2+}$, it can be found that the decrease of $R_{1}$ in the EB-DNA systems is related to the decrease of $r$ too. As a result, the variation of the surface charge distribution on DNA chains due to EB binding to DNA is confirmed again by the decrease of $R_{1}$ of ${ }^{23} \mathrm{Na}$ NMR in the EB-DNA systems.

\section{CONCLUSIONS}

The DNA cholesteric phase is sensitive to the intercalator EB. In the higher concentration of $\mathrm{Mg}^{2+}$, the pitch in the EB-DNA solutions is smaller than that in native DNA. At the same time, the fraction of the liquid crystal phase in EB-DNA systems is greater than that in the EB-free systems at the same $\mathrm{Mg}^{2+}$ concentration. The influence of $\mathrm{EB}$ binding on the DNA chains in the liquid crystalline phase results from multiple factors: stereo structure, surface charge distribution, stiffness of DNA, and so on. The effects of EB on the DNA liquid crystalline behavior is mainly due to the variation of the surface charge distribution, which results from EB blocking counterion binding, and it is also confirmed by the variation of the peak splitting in the ${ }^{23} \mathrm{Na}$ NMR spectra and the decrease of relaxation rate $R_{1}$ of ${ }^{23} \mathrm{Na}$ NMR.

Acknowledgment. Financial support by the National Natural Science Foundation of China is greatly appreciated.

\section{REFERENCES}

1. A. Iihara, K. Sato, and K. Hozumi, et al., Polym. J., 34, 184 (2002).

2. M. S. Yeom and J. Lee, J. Chem. Phys., 123, 144906 (2005).

3. P. Bour, V. Andrushchenko, M. Kabelac, and V. Maharaj, J. Phys. Chem. B, 109, 20579 (2005).

4. S. Satoh, B. Fugetsu, and M. Nomizu, et al., Polym. J., 37, 94 (2005).

5. S. Rikimaru, Y. Wakabayashi, and M. Nomizu, et al., Polym. J., 35, 255 (2003).

6. G. Braun, K. Inagaki, and R. A. Estabrook, et al., Langmuir, 21, 10699 (2005).

7. S. Takenaka, Polym. J., 36, 503 (2004).

8. F. Livolant and A. Leforestier, Prog. Polym. Sci., 21, 1115 (1996).

9. K. Kassapidou and W. Jesse, et al., Biopolymers, 46, 31 (1998).

10. T. E. Strzelecka and R. L. Rill, Biopolymers, 30, 57 (1990).

11. S. I. Inatomi, Y. Jinbo, and T. Sato, et al., Macromolecules, 25, 5013 (1992).

12. F. Livolant, Eur. J. Cell Biol., 33, 300 (1984).

13. C. Robinson, Tetrahedron, 13, 219 (1961).

14. R. L. Rill, F. Livolant, and H. C. Aldrich, et al., Chromosoma, 980, 280 (1989).

15. K. Merchant and R. L. Rill, Biophys. J., 73, 3154 (1997).

16. N. Akimenko, V. Kleinwachter, and Y. Yevdokimov, FEBS., 156, 58 (1983).

17. T. E. Strzelecka and R. L. Rill, J. Phys. Chem., 96, 7796 (1992).

18. G. Gottarelli, G. P. Spada, P. Mariani, and M. M. De Morais, Chirality, 3, 227 (1991).

19. A. Catte and F. Cesare Marincola, et al., J. Biomol. Struct. Dyn., 20, 99 (2002).

20. F. Cesare Marincola, G. Saba, and A. Lai, Phys. Chem. Chem. Phys., 5, 1678 (2003).

21. A. A. Kornyshev and S. Leikin, Phys. Rev. E, 62, 2576 (2000).

22. R. Bruinsma, Phys. Rev. E, 63, 061705 (2001).

23. A. A. Kornyshev, S. Leikin, and S. V. Malinin, Eur. Phys. J. 
E, 7, 83 (2002).

24. G. L. Eichhorn and Y. A. Shin, J. Am. Chem. Soc., 90, 7323 (1968).

25. J. Duguid, V. A. Bloomfield, and J. Benevides, et al., Biophys. J., 65, 1916 (1993).

26. J. Duguid, V. A. Bloomfield, and J. Benevides, et al., Biophys. J., 69, 2623 (1995).

27. T. E. Strzelecka and R. L. Rill, J. Am. Chem. Soc., 109, 4513 (1987).

28. A. Catte, F. Cesare Marincola, and A. Lai, et al., Biomacromolecules, 5, 1552 (2004).

29. T. E. Strzelecka and R. L. Rill, Macromolecules, 24, 5124
(1991).

30. A. Stroobants, H. N. W. Lekkerkerker, and Th. Odijk, Macromolecules, 19, 2232 (1986).

31. J. Sigmon and L. L. Larcom, Electrophoresis, 17, 10, 1524 (1996).

32. T. Kubar, M. Hanus, and F. Ryjacek, et al., Chem. Eur. J., 12, 280 (2005).

33. A. R. Khokhlov and A. N. Semenov, Macromolecules, 17, 2678 (1984).

34. F. Cesare Marincola, M. Casu, and G. Saba, et al., Chem. Phys. Chem., 2, 569 (2001).

35. T. E. Strzelecka and R. L. Rill, Biopolymers, 30, 803 (1990). 